out something that has always been latent in every branch of science, namely, its close linkage at some point with industrial practice, either on the side of production or of technological research. It is not surprising, therefore, that students in pure and in applied science, in addition to those in engineering proper, should seek the opportunity of adding to their experience by taking part in industrial life when the opportunity presents itself. This is underlined in the recent report, for the year ending October, 1942 , on the vacation apprenticeship scheme in operation at the Imperial College of Science and Technology. The scheme is sponsored by the Imperial College Union, and is under the chairmanship of Prof. H. Levy, representing the governing body.

During the past year, 340 students have spent on the average nearly six weeks in research departments and in works, assisting with special investigations, studying the productive processes and the schemes of organization. Some 170 of the foremost firms of Great Britain and many Government departments have willingly co-operated with the Committee in this venture, and have been sufficiently interested to write reports on progress. The scheme has been extended to cover intending students in the summer vacation prior to entry, provided they have reached the Intermediate B.Sc. standard. Last year 32 students entered the scheme at this stage. Apart from the financial return to the students themselves, it is clear that this will give them experience that must react very favourably on their capacity to assimilate the more theoretical studies with which they are necessarily concerned at college; and the fact that the proportion of students of chemistry, physics and mathematics availing themselves of the opportunity presented is steadily increasing is an indication that the scheme meets a real need. Its educational consequences will be well worth watching.

\section{Government Grant to Universities}

Sir Krngsuey Wood, Chancellor of the Exchequer, has announced, in the form of a written reply to a question by Sir E. Graham-Little, the Government's policy with regard to financial support of the universities of Great Britain. $\mathrm{H}_{\Theta}$ said that, although the impact of the War on university finance has so far been less severe than was expected, the Government has maintained unchanged the annual provision for university grants at $£ 2,149,000$. This policy was adopted in view of the vital part played by the universities in the life of the country, their essential contributions towards the national effort in war-time, and the prospect that immediately after the War they will be faced with very large demands on their funds in order to resume normal activities. These considerations have lost none of their force, and the Government, after considering a report from the University Grants Committee, has again decided to maintain the provision at its existing level.

\section{Swedish Forest Products}

According to the Swedish International Press Bureau, a survey of Sweden's production of forest products of a chemical nature was recently given by Mr. Otto Cyren, director of the Swedish Chemical Office. Speaking of chemical pulp, one of Sweden's most outstanding export products in normal times, he said that Sweden is in a very good position in respect of quality, as the slowly growing timber in northerly regions gives very long fibres, and consequently the strongest pulp and paper are obtained from it. The most important by-product of the sulphite pulp production is sulphite spirit, which up to most recent years was the only product recovered. Mixed with petrol, it was of importance as a motor fuel. The purity of the rectified spirit now surpasses that obtained from grain and potatoes, and it is therefore used also for human consumption. Researches on the possibility of using sulphite spirit as the basis of more highly developed products were not initiated until the present crisis made the matter urgent. As an instance he described the work carried on by the Mo and Domsjo Company. In 1941 this company completed a factory for the production of sulphite spirit with a capacity for 10 million litres of 95 per cent spirit a year. At this factory intensive research work is going on, with the view of producing various synthetic products from the spirit. From the black lye obtained in the sulphite pulp process there are produced inter alia certain crude acids, the first factory for using this raw product having been built at the Bergvik och Ala pulp mill. The sebacic acid produced here, called 'pine fatty acid', is used to replace fat in washing mediums, as a substitute for linseed oil in paints, etc.

The output of charcoal in Sweden has trebled in the last couple of years, mainly due to the extensive producer-gas traction of motor-cars, and the byproducts from the carbonization are now being recovered more carefully than before. The charring of old tree stumps, with their high content of rosin, alone gives about 20,000 tons of tar a year. Wood tar is now used as motor fuel for fishing boats in place of crude oil, and has probably saved the Swedish high-sea fisheries from total stoppage. It is also used for the production of lubricants. In summing up the situation for the Swedish forest products industry, Mr. Cyren stated that in 1941 the Swedish exports of woodstuffs had declined by about one third, and the pulp and paper by two thirds, compared with the pre-war level. But in compensation the forests, by supplying cattle feed, wood fuel, motor fuel, lubricants, textile material, fatty oils, and a good many other useful products, have saved the country from catastrophe.

\section{Variation in $\delta$ Ursæ Majoris}

Mr. F. M. Holborn suspected at the end of August that this star was fainter than usual, and this sus. picion has since been confirmed by Mr. N. F. Knight, who observed it in North Africa. His latest estimate of its magnitude on December 10 was $3 \cdot 8-3 \cdot 9$, and on January 14 and $15 \mathrm{Mr}$. Holborn found that its magnitude was $3 \cdot 7$ (normal mag. $3 \cdot 4$ ).

\section{Announcements}

THE following appointments in the Colonial Service have recently been made: $\mathrm{H}$. B. N. Hynes, entomologist, Kenya ; G. R. Groves (horticulturist, Bermuda), curator of the Botanical Gardens, British Guiana.

DR. G. M. B. Dobson's discourse at the Royal Institution on February 12 on "The Air we breathe in Town and Country" will deal with the results of the survey by the Department of Scientific and Industrial Research of the air pollution of Leicester. This was the first detailed survey of the kind ever undertaken in Great Britain. The scientific officer in charge at Leicester was Dr. A. R. Meetham, who was responsible for carrying out the work there. 